\title{
Oswald de Andrade, leitor de Nietzsche, Genealogia, catequese e antropofagia
}

\author{
Rodrigo Ornelas*
}

Resumo: A concepção filosófica oswaldiana da antropofagia como visão de mundo evoca a afirmação de si como motor criador, e não a negação do outro, própria da moral escrava, denunciada por Nietzsche. Entretanto, para Oswald de Andrade, o diagnóstico que Nietzsche faz da cultura ocidental não compreende o potencial primitivo recalcado na América. Oswald diz que sua filosofia antropófaga é também uma realização da filosofia nietzschiana. Acredito que ela pode nos oferecer, entre outras coisas, um caminho para a transvaloração de valores indicada pelo filósofo alemão.

Palavras-chave: Genealogia, Antropofagia, Moralidade, Modernidade.

O percurso proposto a seguir o é de uma aproximação entre dois autores separados mais espacialmente do que temporalmente. Oswald de Andrade nasceu no Brasil em janeiro 1890, um ano depois que Friedrich Nietzsche sofreu o colapso psíquico (em janeiro 1889) que o impossibilitou de continuar produzindo. É natural que o artista da Semana de Arte Moderna brasileira de 1922 seja associado a Nietzsche por uma discussão em torno de temas estéticos. Mas Oswald, a partir do fim da década de 1940, e até a sua morte,

\footnotetext{
** Doutorando em filosofia contemporânea pela Universidade Federal da Bahia (UFBA), Brasil. Correio eletrônico: ornelas.rodrigo@hotmail.com

ORCID: https://orcid.org/0000-0002-2009-6113
} 
Oswald de Andrade, leitor de Nietzsche, Genealogia, catequese e antropofagia

dedicou-se, para além das questões da arte, a fazer filosofia.

É nesse período que Nietzsche se destaca como um dos autores fundamentais para ele. Este texto é uma possibilidade de leitura da proposição teórica de Oswald através de uma problemática nietzschiana, introduzindo antes os pontos que nos serão mais importantes para tal, dentro das perspectivas filosóficas de ambos. Na primeira parte, apresento o recorte da questão nietzschiana sobre a moral que culminará na noção de "transvaloração de todos os valores". Na segunda, exponho em linhas gerais o argumento da "filosofia antropófaga" oswaldiana. Na terceira e última parte, explicito o diálogo de Oswald com Nietzsche em sua elaboração filosófica, apontando um modo de ler a filosofia de Oswald como, também, um caminho para a realização daquela proposta de Nietzsche.

\section{A genealogia da moral em Nietzsche}

Após o marco do seu Zaratustra (1883-85), como sabemos, a obra de Nietzsche detém-se numa excepcional reflexão sobre a moral. No aforismo 186 de Além do bem e do mal, podemos encontrar um panorama do que será sua empreitada naquilo que depois chamou de genealogia. Ali ele dissera:

Tão logo se ocuparam da moral como ciência, os filósofos todos exigiram de si, com uma seriedade tesa, de fazer rir, algo muito mais elevado, mais pretencioso, mais solene: eles desejaram a fundamentação da moral - e cada filósofo acreditou até agora ter fundamentado a moral; a moral mesma, porém, era tida como "dada". (JGB/BM 186, KSA 5.105-6).

Exposta esta fundamental fragilidade, qual seja, de que a moral mesma nunca havia sido investigada pelos filósofos da moral, ele continua, no mesmo aforismo:

O que os filósofos denominavam fundamentação da moral, exigindo-a de si, era apenas, vista à luz adequada, uma forma erudita da ingênua fé na moral dominante, um novo modo de expressá-la, e portanto um 
fato no interior de uma determinada moralidade, e até mesmo, em última instância, uma espécie de negação de que fosse lícito ver essa moral como um problema - em todo caso o oposto de um exame, questionamento, análise, vivissecção dessa mesma fé. (JGB/BM 186, KSA 5.106).

Isso já indica ao que sua construção se pretenderá: ver nessa moralidade um problema; e examiná-la, questioná-la, analisá-la, fazer sua "vivissecção". A tarefa como posta ali, em Além do bem do mal (1886), desenvolve-se no livro seguinte, Genealogia da moral (1887). É essa compreensão da moral em sua "cadeia hereditária", bem como em sua "evolução" (em sentido darwiniano), que nos interessará aqui. O que significou a investigação genealógica da moral por Nietzsche, qual o seu resultado? Podemos dizer: uma narrativa; a descrição de uma perspectiva da modernidade, até sua crise, e uma prescrição.

Em sua análise, Nietzsche aponta que uma moral tem uma história, sendo sempre uma moral entre outras. A moral de seu tempo e na Europa era, ele dizia, "moral de rebanho" e "apenas uma espécie de moral humana, ao lado da qual, antes da qual, depois da qual muitas outras morais, sobretudo mais elevadas, são ou deveriam ser possíveis" (JGB/BM 202, KSA 5.124). Posta em exame, compreendemos um modo de ser da moral, mas, ainda segundo Nietzsche, como vemos, também um modo de poder ser (ou dever ser) da moral.

Uma determinada moralidade ascende e consolida-se culturalmente, de modo que seus valores apenas aparentemente são universais. Qual a cultura moral que determinava aqueles valores que Nietzsche tinha em vista na Europa do século XIX, qual a sua "origem" (como ele mesmo dissera no prólogo da Genealogia)? O judaísmo virado em cristianismo ${ }^{1}$. Antes de se estabelecer como máxima universal, a moral cristã, no entanto, era a moral de escra-

1 Cf., p. ex., o § 195, de Além do bem e do mal (JGB/BM 195, KSA 5.116-7) ou os §9 e §16 da primeira dissertação de Genealogia da moral (GM/GM I 9 e 16, respectivamente KSA 5.269-70 e 5.285-8). 
Oswald de Andrade, leitor de Nietzsche, Genealogia, catequese e antropofagia

vos (Sklave). Por isso é assim que Nietzsche chamará essa moral no interior da qual os filósofos e não filósofos europeus moviam-se àquela altura. No fragmento conhecido de Lenzer Heide de junho de $1887^{2}$ Nietzsche questiona: "Quais vantagens oferecia a hipótese moral cristã?" (Nachlass /FP 5 [71], KSA 12.211). Sua resposta é que ela deu ao homem "um valor absoluto, em oposição à sua pequenez e casualidade na corrente do devir e do perecer" (Nachlass /FP 5 [71], KSA 12.211), mas também "servia aos advogados de Deus" e "estabeleceu no homem um saber sobre valores absolutos" (Nachlass /FP 5 [71], KSA 12.211); concluindo que "a moral era o grande antídoto contra o niilismo prático e teórico." (Nachlass /FP 5 [71], KSA 12.211).

Devemos nos perguntar, então, quais as consequências de uma moral estabelecida por um povo que, imediatamente antes, era escravizado: "A moral tratou os possuidores de poder, os violentadores, os 'senhores' em geral, como inimigos, contra os quais o homem comum tem de ser protegido, isto é, primeiramente encorajado, fortalecido." (Nachlass /FP 5 [71], KSA 12.214). O resultado num quadro de valores é exemplificado no aforismo 14 da primeira dissertação da Genealogia:

"A fraqueza é mentirosamente mudada em mérito (...). e a impotência que não acerta contas é mudada em 'bondade; a baixeza medrosa, em 'humildade'; a submissão àqueles que se odeia em 'obediência' (há alguém que dizem impor esta submissão - chamam-no Deus). O que há de inofensivo no fraco, a própria covardia na qual é prodígio, seu aguardar-na-porta, seu inevitável ter-de-esperar, recebe aqui o bom nome de 'paciência, chama-se também 'a virtude'; o não-poder-vingarse chama-se não-querer-vingar-se, talvez mesmo perdão ('pois eles não sabem o que fazem - somente nós sabemos o que eles fazem!'). Falam também do 'amor aos inimigos' - e suam ao falar disso." (GM/GM I 14, KSA 5.281-2).

2 A Genealogia foi escrita em julho do mesmo ano.

Cad. Nietzsche, Guarulhos/Porto Seguro, v.41, n.3, setembro-dezembro $2020 \mid 223$ 
Foi o cristianismo que efetuou a primeira transvaloração de todos os valores. Mas ele o fez tendo por força a noção de verdade (Nachlass /FP 5 [71], KSA 12.211-2), cristã e platônica, que mais à frente volta-se contra o próprio cristianismo. É a morte de Deus e a ascensão de novos ídolos (o Homem, o Estado, a Ciência). A verdade perseguiu aqueles que afirmavam conhecer (ou ser) "a verdade". $\mathrm{O}$ sintoma de que aquela moralidade entrava em decadência era o niilismo (Nachlass /FP 5 [71], KSA 12.216), contra o qual esta moral ascendeu enquanto "antídoto": "Uma interpretação sucumbiu; mas porque ela valia como $\boldsymbol{a}$ interpretação, parece como se não houvesse nenhum sentido na existência, como se tudo fosse em vão." (Nachlass /FP 5 [71], 4, KSA 12.212). Agora, então, novamente o niilismo: "O homem preferirá ainda querer o nada a nada querer." (GM/GM III 28, KSA 5.412). A genealogia daquela moral na qual a filosofia e a cultura estavam imersas indicava o caminho da terapêutica: uma nova transvaloração de todos os valores.

\section{A antropofagia como Weltanschauung}

O modernismo nas vanguardas artísticas da América Latina caracterizou-se pela tensão fundadora daquelas nações pós-coloniais, a saber, a de situarem-se entre suas raízes locais e cosmopolitas. Aos olhos dos modernistas, a arte regionalista padecia de certo imobilismo incongruente com o mundo moderno; por outro lado, repetir a estética estrangeira seria reincidir no paradigma de colônia ${ }^{3}$. No Brasil, o Manifesto da Poesia Pau-Brasil (1924), de Oswald de Andrade, indicava a reivindicação de uma "arte de exportação" por este que foi um dos principais agitadores da Semana

3 Antônio Cândido, p. ex., chamou esta tensão de "dialética", entre um localismo e um cosmopolitismo: "Pode-se chamar dialético a este processo porque ele tem realmente consistido numa integração progressiva da experiência literária e espiritual, por meio da tensão entre o dado local (que se apresenta como substância da expressão) e os moldes herdados da tradição europeia (que se apresentam como forma da expressão)". (Cândido, 2004, p.117). No mesmo texto, mais à frente, ele apontará a antropofagia oswaldiana como representante do "momento mais tenso da dialética modernista" (Cândido, 2004, p.172). 
Oswald de Andrade, leitor de Nietzsche, Genealogia, catequese e antropofagia

de Arte Moderna, de 1922. A resposta de Oswald àquela tensão é desenvolvida no seu manifesto seguinte, o Manifesto Antropófago (1928), quando o autor insere a antropofagia como princípio, ao mesmo tempo próprio (pois é característico de um povo local), e atualizador, uma vez que se transforma metabolizando o outro (i.e., preservá-lo, metabolizado, em mim)4 . Desde 1928 o uso da noção de antropofagia extrapolava a questão artística, tornando-se elemento de uma questão nacional - cultural e social -, mas também com um potencial teórico que Oswald retomaria a partir de 1945, para propor uma formulação filosófica. É em 1950, então, que essa formulação adquire uma elaboração formal.

No ensaio A crise da filosofia messiânica $(1950)^{5}$, Oswald de Andrade trata inicialmente de caracterizar a antropofagia como uma Weltanschauung, uma visão de mundo (Andrade, 2011a, p.138.). Baseado na observação de Montaigne, em seus Ensaios, de que a cultura canibal não seria mais bárbara - do que, por exemplo, a cultura de "queimar aos poucos" um homem "a pretexto de devoção e fé" (Montaigne, 2004, p.199.) - mas apenas uma outra cultura, uma visão de mundo autônoma, Oswald se vale filosoficamente desta experiência indígena-brasileira como uma poderosa metáfora. A antropofagia deu nome a uma das mais importantes revistas do modernismo brasileiro (a Revista de Antropofagia, em

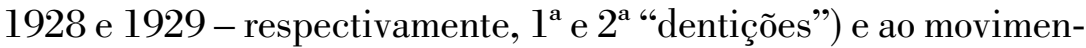
to artístico-cultural-intelectual que dela se seguiu. Na antropofagia experimenta-se a absorção do outro não para destruí-lo, mas para tomá-lo de modo próprio ${ }^{6}$.

4 Antropofagia como forma de se “(...) assimilar sob espécie brasileira a experiência estrangeira e reinventá-la em termos nossos, com qualidades locais ineludíveis que dariam ao produto resultante um caráter autônomo e lhe confeririam, em princípio, a possibilidade de passar a funcionar por sua vez, num confronto internacional, como produto de exportação." (Haroldo de Campos apud Veloso, 2008, p.242).

5 Submetido a exame na Universidade de São Paulo naquele ano, em uma má sucedida tentativa de ingresso na instituição como livre docente - na ocasião, a vaga foi assumida pelo prof. João Cruz Costa.

6 “Comer o inimigo não como forma de ‘assimilá-lo’, torná-lo igual a mim, ou de ‘negá-lo’ para

Cad. Nietzsche, Guarulhos/Porto Seguro, v.41, n.3, setembro-dezembro $2020 \mid 225$ 
Enquanto uma Weltanschauung, a antropofagia faz, para Oswald, contraponto ao Messianismo. Como sugere Benedito Nunes, "é a conquista espiritual dos jesuítas que se transfere à ação e ao pensamento do Messianismo (...). São messiânicas as religiões de salvação e as filosofias da transcendência" (Nunes, 2011, p.46). $\mathrm{Na}$ narrativa de Oswald, dois "hemisférios culturais" dividiram a história em Matriarcado e Patriarcado: o primeiro é o "mundo do homem primitivo", de Weltanschauung antropófaga, enquanto o segundo é o mundo do "civilizado", de Weltanschauung messiânica (Andrade, 2011a, p.139). Em sua tese, Oswald defende que a cultura messiânica está em declínio e sendo "dialeticamente" substituída pela antropófaga, "como síntese ou terceiro termo" (Andrade, 2011 a, p.204). O elemento matriarcal-antropófago foi dado, no primeiro termo, pelo "homem natural", da Idade do Ócio (da América pré-colombiana); o patriarcal-messiânico, segundo termo, pelo "homem civilizado", da Idade da Técnica (Andrade, 2011a, p.141) (da Europa moderna). Na síntese está o "homem natural tecnizado", que "pela técnica e pelo progresso social e político (...) deixa a sua condição de escravo e penetra de novo no limiar da Idade do Ócio. É um outro Matriarcado que se anuncia" (Andrade, 2011a, p.145). Novamente, então, retornaria, para Oswald, o paradigma antropófago. A filosofia da história oswaldiana é a de um tempo-histórico circular.

Em um cálculo dialético, o pensamento europeu construiu suas utopias modernas a partir do encontro com o "homem natural" das Américas, entendendo-o como o "primeiro termo" de si. O europeu olhou o povo que encontrou na outra margem do Atlântico e acreditou olhar para si no passado, em estado "primitivo", não como um outro humano, uma outra "natureza humana". Daí Oswald observar a importância para a Europa das descrições divulgadas por Américo Vespúcio a respeito do Novo Mundo, que chegou a

afirmar a substância identitária de um Eu, mas tampouco transformar-se nele como um outro Eu, mimetizá-lo", mas "Transformar-se, justo ao contrário, por meio dele, transformar-se em um eu Outro (...)" (Viveiros de Castro, 2016, p.15-6). 
Oswald de Andrade, leitor de Nietzsche, Genealogia, catequese e antropofagia

receber seu nome: "Quem tinha encontrado o continente fora Colombo. Mas quem tinha fixado o homem natural era Vespúcio"; foram suas cartas que "criaram as Utopias" (Andrade, 2011f, p.315). Por isso, o Manifesto Antropófago afirmava: "Sem nós a Europa não teria sequer sua pobre declaração de direitos do homem. (...) $\mathrm{O}$ contato com o Brasil Caraíba. (...) O homem natural. Rousseau." (Andrade, 2011c, p.68); e, mais à frente: "Já tínhamos o comunismo" (Andrade, 2011c, p.70) ${ }^{7}$. Só que este homem natural coexistindo com aquele homem civilizado, e que engendrou aquelas utopias, só consumou-se, de fato, na experiência pós-colonial, nas nações que se fundaram a partir desse encontro. Assim, para Oswald, a Europa não poderia realizar esta síntese enquanto padecesse de sua Weltanschauung messiânica.

\section{Oswald leitor de Nietzsche ou Nunca fomos catequisados}

Podemos dividir a obra de Oswald em três fases bem definidas: (1) a da construção artístico-cultural, que culmina na antropofagia, até 1930, (2) a da militância marxista, de 1930 a 1945, e (3) a filosófica, onde a antropofagia é retomada como filosofia, de 1945 até sua morte, em 1954. É sabido que ainda naquela primeira fase Oswald leu e foi marcado pela obra de Nietzsche, especificamente por Assim falou Zaratustra, em 1920 (Andrade, 2009, p.202). Em sua fase marxista tece duras críticas ao filósofo alemão, quando entendia haver alguma aproximação entre as ideias de Nietzsche e as de Hitler ${ }^{8}$. Em seguida, após 1945, Oswald não só reconcilia-se

7 Sobre isso, ver também a tese de Afonso Arinos de Melo Franco, $O$ índio brasileiro e a Revolução Francesa (1937), segundo Oswald, "um dos melhores documentos" produzidos pela literatura brasileira "antropofágica" (Andrade, 2011f, p.316).

8 Em um volume publicado postumamente como Dicionário de bolso, Oswald anotava definições para personagens históricos. No "verbete" Nietzsche ele escreveu: "Super-Hitler" (Andrade, 2007, p.62). É importante destacar que nesse momento, marcado pela segunda grande guerra, não era exclusividade de Oswald associar ambos, especialmente em círculos marxistas.

Cad. Nietzsche, Guarulhos/Porto Seguro, v.41, n.3, setembro-dezembro $2020 \mid 227$ 
com Nietzsche, chegando a ponderar que "se Hitler visitou a casa de Nietzsche (...), Nietzsche nunca subiria as escadarias da Chancelaria do Reich" (Andrade, 2011b, p.150), como faz dele um dos principais autores que irão enfatizar a antropofagia. Nessa terceira fase, Nietzsche é um dos pilares que embasam o pensamento filosófico de Oswald.

Na concepção oswaldiana, a análise genealógica de Nietzsche sobre a Europa é correta e diz respeito também à América moderna. Mas apenas em parte. Na "genética" da moralidade americana também está o cristianismo europeu, "moral de rebanho"; no entanto, a cosmovisão que recepciona o cristianismo e com ele constrói uma modernidade na América tem ainda um elemento genético fundamental, que, segundo Oswald, preservou-se: "Com toda a coação e a libidinagem da gente branca, não foi, no entanto, destruído o que melhor restava no natural das Américas. A cultura residiu no fundo das florestas, como recusa a toda força escravizante" (Andrade, 2011g, p.446). Leitor de Nietzsche, ele sabe que os valores europeus determinados pela ascensão do cristianismo são os valores morais do escravo, e observa que "O escravo só podia existir na condição miserável a que estava reduzido, com a esperança messiânica da outra vida" (Andrade, 201la, p.164) - em Nietzsche encontramos que aquilo que ao escravo "serve de consolo por todo o sofrimento da vida" é a esperança no que chamaram de "Juízo Final', o advento do seu reino, do "Reino de Deus" (GM/ GM I 14, KSA 5.283). Lembremos, então, que das duas únicas sentenças que se repetem no Manifesto de 1928, uma é "Nunca fomos catequizados". Em 1657, no seu Sermão do Espírito Santo, o padre Antônio Vieira referiu-se à dificuldade de catequese dos índios no Brasil, comparando estátuas de mármore e de murta, quando as primeiras mantém o sólido resultado esculpido e as segundas precisam frequente e insistentemente de trato para manter a forma ${ }^{9}$ :

9 "Há outras nações (e estas são as do Brasil) que recebem tudo o que lhes ensinam, com grande docilidade e facilidade, sem argumentar, sem replicar, sem duvidar, sem resistir; mas são estátuas de Murta, que em levantando o mão o jardineiro, logo perdem a nova figura e tornam à 
Oswald de Andrade, leitor de Nietzsche, Genealogia, catequese e antropofagia

"Outros gentios são incrédulos até crer; os Brasis ainda depois de crer são incrédulos. Em outros Gentios a incredulidade é incredulidade, e a Fé é Fé; nos Brasis a mesma Fé, ou é ou parece incredulidade." (Vieira, 2014, p.423). Para Oswald:

O que aterrava Nietzsche era ver o mundo caminhar para uma espécie de cristianismo sem Deus, essa espécie de socialismo de padre que as famosas encíclicas inutilmente açularam e puseram na ordem do dia. $\mathrm{O}$ que escapou à observação de Nietzsche, como à de Marx e Engels, é que havia um potencial de primitivismo recalcado por séculos sob o domínio fraco das elites burguesas. (Andrade, 2011g, p.398).

No final da Genealogia da moral, Nietzsche diz que estava preparando uma obra, que não foi concluída, chamada "Vontade poder: ensaio de transvaloração de todos os valores" (GM/GM III 27, KSA 5.409). Lendo outras obras de Nietzsche podemos, claro, extrair dali o que seria o caráter mais prescritivo da sua filosofia moral. Mas podemos também extraí-lo das consequências filosóficas de Nietzsche. É o que entendo que acontece com Oswald: oferecer uma perspectiva programática para essa transvaloração. Na Europa, a Idade da Técnica foi a negação do Ócio: “Na moral de escravos se forjaria a técnica e se desenvolveriam as forças produtivas da sociedade e, por oposição, suas forças libertárias" (Andrade, 2011b, p.153). Em uma Weltanschauung antropófaga, não a negação, mas a realização da técnica nos devolverá o ócio, numa dialética histórica progressista, circular e afirmativa.

A antropofagia afirma o contato com o cristianismo sem a sua sacralização, ou seja, podendo participar da sua cultura moral, superando-a (em sentido dialético-antropófago) - é o Bispo Sardinha sendo comido pelos Caetés em $1556^{10}$. Voltando àquele aforismo oswaldiano de destaque, o Manifesto Antropófago diz ainda: "Nunca fomos catequizados. Fizemos foi Carnaval. O índio vestido de

bruteza antiga e natural, e a ser mato como dantes eram." (Vieira, 2014, p.425).

10 É essa a referência que Oswald usa para datar o Manifesto Antropófago ("Ano 374 da Deglutição do Bispo Sardinha” - Cf. Andrade, 2011c, p.74), pois ali começa o Brasil.

Cad. Nietzsche, Guarulhos/Porto Seguro, v.41, n.3, setembro-dezembro $2020 \mid 229$ 
senador do Império. (...)" (Andrade, 2011c, p.70); e depois: “Absorção do inimigo sacro. Para transformá-lo em totem. A humana aventura. Terrena finalidade" (Andrade, 2011c, p.70). Ao mesmo tempo metáfora, diagnóstico e terapêutica (Nunes, 2011, p.21), antropofagia é "transformação permanente do tabu em totem" (Andrade, 2011c, p.69); é permanente autocriação afirmativa ${ }^{11}$. Em entrevista a Paulo Mendes Campos, em agosto de 1947, Oswald dirá: "O homem é um anel na eterna cadeia da devoração. São estes os valores que já estão aí, misturados, é verdade, na escória e na alma que vem com o ouro da nova idade. A beleza é uma eterna batalha." (Andrade, 2009, p.216). No aforismo 10 da primeira dissertação da Genealogia, Nietzsche dissera:

A rebelião escrava na moral começa quando o próprio ressentimento se torna criador e gera valores: o ressentimento dos seres aos quais é negada a verdadeira reação, a dos atos, e que apenas por uma vingança imaginária obtêm reparação. Enquanto toda moral nobre nasce de um triunfante Sim a si mesma, já de início a moral escrava diz Não a um "fora", um "outro", um "não-eu" - e este Não é seu ato criador. (GM/GM, I 10, KSA 5.270).

O que é a perspectiva antropófaga, senão uma grande rejeição à negação como motor criador? Nem a negação de si na catequese, nem a negação ressentida do outro. Antropofagia é afirmação autocriativa de si. No rito antropófago há um diálogo fundamental, e que assombrava os missionários cristãos, travado entre o prisioneiro e seu futuro assassino: o que será comido afirma que será vingado por sua tribo, assim como já comeu outros daquela tribo que ali vingavam seus ancestrais devorados, comendo-o, numa fala não sobre transcendência, mas apenas sobre passado e futuro, que garante a permanência temporal, cíclica, de ambas as tribos ${ }^{12}$. Não há perdão

11 "Pois é evidentemente primordial que se restaure o sentido de comunhão do inimigo valoroso no ato antropófago. (...) Trata-se apenas da transformação do Tabu em Totem, isto é, do limite e da negação em elemento favorável" (Andrade, 2011b, p.153).

12 Cf. Cunha, 2009, p.86-90. 
Oswald de Andrade, leitor de Nietzsche, Genealogia, catequese e antropofagia

nem penitência. Não há culpa, ressentimento ou compaixão. E é dessa visão de mundo que Oswald quer extrair uma perspectiva filosófica. Em um caderno de memórias, Oswald anotou:

Sofro como Dostoiévski e arrisco como Nietzsche. Isso fez de meus dias um bolo dramático sem fim. Adotei de há muito um completo ceticismo em face da civilização ocidental que nos domou. Acredito que ela está em seus últimos dias, vindo à tona uma concepção oposta - a do homem primitivo, que o Brasil podia adotar como filosofia. $\mathrm{O}$ ocidente nos mandou com o messianismo todas as ilusões que escravizam. Montaigne, no seu grande capítulo dos Essais onde exalta les cannibales, foi o primeiro que viu o caminho novo - o dado pela revolta e pelo estoicismo do índio. Não se trata da contrafação cristã de Rousseau que é uma deformação. Evidentemente o que eu quero não é retorno à taba e sim ao primitivo tecnizado. (Andrade, 2011e, p.204)

O antropófago, Oswald dizia já em 1929, “não é o índio de rótulo de garrafa", mas "o antropófago de knicker-bockers e não o índio de ópera" (Andrade, 1929, p.10). Não o índio do passado, mas, como queria Darcy Ribeiro, o "homem do futuro" (Ribeiro, 2008, p.103) - ao dizer que "Lévi Strauss confunde antropologia com Arqueologia". Futuro é uma das palavras fundamentais no modernismo (que tem como marco um manifesto justamente chamado defuturista). Não um futuro que quer descolar-se de sua atualidade, como ressalvaram os modernistas brasileiros em Klaxon (1922), mas futuro porque quer tomar seu tempo e contexto como matéria de reflexão e avançar, realizar. Gilberto Freyre definiu Oswald como o modernista brasileiro que caminhou "sempre, e decididamente, para o futuro" (Freyre, 1965, p.08). Essa palavra também aparece no subtítulo de Além do bem e do mal: "prelúdio a uma filosofia do futuro". E o segundo momento nietzschiano deste modo de tratar a moral no centro de uma reflexão filosófica, a sua Genealogia da moral, encerra-se apontando para um projeto de transvaloração dos valores ocidentais modernos. Oswald diz expressamente que sua proposição filosófica pretende ser uma realização nietzschiana: “É preciso dar o passo de Nietzsche na direção do super-homem. 


\begin{abstract}
Atingir a filosofia da devoração. A antropofagia." (Andrade, 2011d, p.448). Acredito que a antropofagia, como proposta pelo nietzschiano Oswald de Andrade, pode ser pensada como uma assim "filosofia do futuro", que sugere, entre outras coisas, também um caminho de realização para aquele projeto de transvaloração.
\end{abstract}

\title{
Oswald de Andrade as a Nietzsche reader. Genealogy, ca- techism and anthropophagy
}

\begin{abstract}
The Oswaldian philosophical conception of anthropophagy as "world view" evokes the affirmation of self as creative motor, not as negation of the other, proper to slave morality denounced by Nietzsche. But, for Oswald de Andrade, the occidental culture's diagnostic made by Nietzsche does not comprehend the primitive potential repressed in America. Oswald says that his anthropophagical philosophy is also an achievement of Nietzsche's philosophy. I believe that it can offer us, among other things, a path to the revaluation of values indicated by the German philosopher.
\end{abstract}

Key words: Genealogy, Anthropophagy, Morality, Modernity. 
Oswald de Andrade, leitor de Nietzsche, Genealogia, catequese e antropofagia

\section{Referências}

ANDRADE, Oswald de (2011a). "A crise da filosofia messiânica". In: . A utopia antropofágica. São Paulo: Globo, p. 138-215. . (2007). Dicionário de bolso. São Paulo: Globo. . (2011b). "Informe sobre o modernismo". In: . Estética e Política. São Paulo: Globo, p. 144-155. . (2011c). "Manifesto Antropófago". In: A utopia antropofágica. São Paulo: Globo, p. 67-74.

. (2011d). "Mensagem ao antropófago desconhecido (da França Antártica)". In: . Estética e Política. São Paulo: Globo, p. 447-449.

. (2011e). "Notas para o meu Diário confessional". In: . Estética e Política. São Paulo: Globo, p. 198-205. . (2011f). "O achado de Vespúcio". In: A utopia antropofágica. São Paulo: Globo, p. 311-317. . (2011g). "O antropófago". In: . Estética e Política. São Paulo: Globo, p. 374-446. . (2009). Os dentes do dragão: entrevistas. São Paulo: Globo. . (1929). "Uma adesão que não nos interessa". In: Revista de Antropofagia ( $2^{a}$ dentição). Edição fac-simiar. N. 10 (Suplemento do Diário de São Paulo, 12 jun., p. 10).

CÂNDIDO, Antônio (2010). "Literatura e cultura de 1900 a 1945". In: Literatura e Sociedade. Rio de Janeiro: Ouro sobre Azul, p. 117-145.

CUNHA, Manuela Carneiro da (2009). Cultura com Aspas e outros ensaios. São Paulo: Cosac Naify.

FREYRE, Gilberto (1965). "Modernidade e modernismo na arte política". In: ___ Seis conferências em busca de um leitor. Rio de Janeiro: José Olympio Editora, p. 03-21.

MONTAIGNE, Michel de (2004). "Ensaios". In: Montaigne (Volume 1) - Coleção Os Pensadores. São Paulo: Nova Cultural.

NIETZSCHE, Friedrich (2005). Além do bem e do mal: prelúdio a uma filosofia do futuro. São Paulo: Companhia das Letras. 
Ornelas, R

. (2009). Genealogia da moral: uma polêmica. São Paulo: Companhia das Letras. . (2013). "O niilismo europeu”. Tradução: Clademir Araldi, Estudos Nietzsche, Curitiba, v. 3, n. 2, jul./dez, p. 249-255.

. (1988). Sämtliche Werke: Kritische Studienausgabe (KSA). Berlin/ München: Walter de Gruyter/ dtv.

NUNES, Benedito (2011). "Antropofagia ao alcance de todos". In: ANDRADE, Oswald de. A utopia antropofágica. São Paulo: Globo, p. 07-56.

RIBEIRO, Darcy (2008). Utopia Brasil. São Paulo: Hedra.

VELOSO, Caetano (2008). Verdade tropical. São Paulo: Companhia das Letras.

VIEIRA, Antônio (2014). Sermões - Tomo I. São Paulo: Hedra.

VIVEIROS DE CASTRO, Eduardo (2016). "Prefácio". In: AZEVEDO, Beatriz. Antropofagia - Palimpsesto Selvagem. São Paulo: Cosac Naify.

Enviado: 30/01/2020

Aceito:15/04/2020 